\title{
Allosteric regulation of the calcium-sensing receptor in obese individuals
}

\author{
YONGHAN HE ${ }^{1,2}$, BEN PERRY $^{3}$, MINGXIN BI $^{1}$, HUI SUN $^{4}$, TIANTIAN ZHAO ${ }^{5}$, \\ YING LI $^{1}$ and CHANGHAO SUN ${ }^{1}$
}

\begin{abstract}
${ }^{1}$ National Key Discipline of Nutrition and Food Hygiene, Public Health College, Harbin Medical University, Harbin, Heilongjiang 150081; ${ }^{2}$ State Key Laboratory of Genetic Resources and Evolution, Kunming Institute of Zoology, Chinese Academy of Sciences, Kunming, Yunnan 650223, P.R. China; ${ }^{3}$ Aquatic and Crop Resource Development, Life Sciences Branch, National Research Council Canada, Charlottetown, Prince Edward Island C1A 4P3, Canada;

${ }^{4}$ Emergency Department, The Second Affiliated Hospital, Harbin Medical University, Harbin, Heilongjiang 150001, P.R. China; ${ }^{5}$ Department of Psychology, University of Toronto, Toronto, Ontario M1C 1A4, Canada
\end{abstract}

Received March 8, 2013; Accepted May 24, 2013

DOI: $10.3892 /$ ijmm.2013.1408

\begin{abstract}
We have previously reported that the calcium-sensing receptor (CaSR) plays an important role in modulating lipid metabolism under low calcium conditions. The aim of this study was to identify possible regulators of CaSR and the mechanisms of action of CaSR in obese individuals. Subcutaneous fat samples were obtained from 10 obese and 10 non-obese males undergoing elective abdominal surgery. Visceral fat pads were obtained from 12 obese and 12 non-obese male rats. Serum lipid, tumor necrosis factor- $\alpha$ (TNF- $\alpha$ ) and interleukin-6 (IL-6) concentrations, as well as the gene and protein expression of $\mathrm{CaSR}$ in the white adipose tissue of obese subjects and rats were determined. Serum total calcium, vitamin D, parathyroid hormone (PTH) and amino acid levels in human subjects were measured. Intracellular calcium and cyclic adenosine monophosphate (cAMP) levels in rat adipocytes were measured by laser scanning confocal microscopy and ELISA, respectively. The results revealed that serum triglyceride (TG), total cholesterol (TC), low density lipoprotein-cholesterol (LDL-C), TNF- $\alpha$, IL-6 and PTH levels were significantly higher in the obese individuals versus the controls. By contrast, serum vitamin $\mathrm{D}$ and amino acid concentrations were lower in the obese individuals versus the controls. In addition, intracellular calcium levels were higher, while cAMP levels were lower
\end{abstract}

Correspondence to: Professor Ying Li or Professor Changhao Sun, National Key Discipline of Nutrition and Food Hygiene, Public Health College, Harbin Medical University, 157 Baojian Road, Nangang, Harbin, Heilongjiang 150081, P.R. China

E-mail: liying_helen@163.com

E-mail: sun2002changhao@yahoo.com

Key words: calcium-sensing recepor, obesity, cytokine, calcium, amino acids in the obese rat adipocytes compared with the control group. However, the gene and protein expression of CaSR in white adipose tissue did not differ between the obese groups and the controls. Thus, these results suggest that CaSR functions not through its expression, but rather through allosteric regulation in obese individuals.

\section{Introduction}

The prevalence of obesity worldwide has progressively increased over the past few decades in the majority of highand low-income countries (1). Obesity and the metabolic pathologies associated are the most common and detrimental metabolic diseases, affecting over $50 \%$ of the adult population. Obesity is a multi-factorial disease that develops from the interaction between genetic, environmental and psychosocial factors (2). Accordingly, identifying any of these factors is beneficial for the prevention and/or treatment of obesity.

The calcium-sensing receptor (CaSR) is a G-proteincoupled receptor that plays a critical role in modulating calcium homeostasis (3). It was cloned from the bovine parathyroid gland by Brown et al in 1993 (4). Subsequently, CaSR has been reported to be expressed in several other organs, where it plays various roles (3). In 2005, Cifuentes et al first cloned CaSR in human omental adipose tissue (5). The activation of CaSR has been shown to induce an antilipolytic effect in adipose cells (6). In a previous study, we demonstrated that the activation of CaSR inhibits lipolysis by mediating the intracellular calcium $\left(\left[\mathrm{Ca}^{2+}\right]_{\mathrm{i}}\right)$ and cyclic adenosine monophosphate (cAMP) pathways in human SW872 cells (7). In addition, we also reported that $\mathrm{CaSR}$ activation promotes adipogenesis by regulating key transcription factors, including peroxisome proliferator-activated receptor $\gamma(\operatorname{PPAR} \gamma)$ and CCAAT element-binding protein $\alpha(\mathrm{C} / \mathrm{EBP} \alpha)(8)$. In another previous study, we demonstrated that $\mathrm{CaSR}$ activation affects fat accumulation in rats fed a low calcium diet (9). These findings collectively suggest the important role of CaSR in the development of obesity. 
CaSR can be stimulated allosterically, by changes in its expression, or by a combination of both (3). CaSR regulates calcium homeostasis by sensing extracellular calcium concentrations and by mediating alterations in parathyroid hormone (PTH) secretion (10). The activation of CaSR produces rapid, transient increases in cytosolic calcium levels by mobilizing calcium from intracellular stores and by increasing calcium influx through voltage-sensitive calcium channels in the cell membrane (11). $\left[\mathrm{Ca}^{2+}\right]_{\mathrm{i}}$ plays an important role in the metabolic disorders of obesity and insulin resistance (12-14). Obese patients usually exhibit elevated basal $\left[\mathrm{Ca}^{2+}\right]_{\mathrm{i}}$ levels in adipocytes (14). Therefore, it is reasonable to assume that CaSR may play a role in the development of obesity by mediating the increase in $\left[\mathrm{Ca}^{2+}\right]_{\mathrm{i}}$ levels and affecting lipogenesis. In addition, extracellular calcium and L-amino acids have been shown to activate CaSR, as evidenced by $\left[\mathrm{Ca}^{2+}\right]_{\mathrm{i}}$ mobilization (15).

Changes in the expression of CaSR may also induce various effects in different tissues (3). The mRNA and/ or protein expression of CaSR is modulated by a variety of substances and biochemical conditions, such as extracellular calcium (16), vitamin D (17) and phosphorus (18). Obesity is associated with a state of low-grade chronic inflammation and this may represent a link between the obese state and health complications associated with obesity, such as cardiovascular disease and insulin resistance (19,20). In 2010, Cifuentes et al reported that obesity-associated pro-inflammatory cytokines increase CaSR protein expression in adipocytes (21) and that CaSR activation elevates pro-inflammatory cytokine expression in human adipose cells and adipose tissue (22), suggesting that inflammatory factors are possible regulators of CaSR in obese individuals. In a previous study, we also found that CaSR expression was induced in the white adipose tissue of rats fed a low calcium diet (9). However, to our knowledge, no studies to date have identified the specific mechanisms of action of CaSR in the white adipose tissue of obese subjects.

In this study, we investigated the gene and protein expression of CaSR in the white adipose tissue of obese human individuals and rats. We also determined the possible regulators of CaSR, such as serum calcium, vitamin D, inflammatory cytokines and amino acids. Our results revealed that obesity produces a state of lower vitamin D and amino acids and a state of higher inflammation, with the adipose tissue CaSR expression remaining unaltered. These data, in conjunction with those from our previous studies, suggest that CaSR functions in the white adipose tissue of human subjects and rats through an allosteric mechanism.

\section{Materials and methods}

Human subjects. Ten obese [aged 18-50 years; body mass index $(\mathrm{BMI}) \geq 28 \mathrm{~kg} / \mathrm{m}^{2}$ ] and 10 non-obese males (aged $18-50$ years; $\mathrm{BMI} \geq 18$ to $\leq 24 \mathrm{~kg} / \mathrm{m}^{2}$ ) undergoing elective abdominal surgery in the Second Affiliated Clinical Hospital of Harbin Medical University, Harbin, China were recruited in this study. To avoid the influence of sex hormones on CaSR gene and protein expression, we recruited only male subjects in this study. Height was measured without wearing shoes by using a steel tape with a maximum of $2 \mathrm{~m}$ and an accuracy of $0.1 \mathrm{~m}$. Body weight was measured using an electronic scale with a dial showing a maximum of $136 \mathrm{~kg}$ and an accuracy of
Table I. Clinical characteristics and serum lipids of obese and normal weight subjects.

\begin{tabular}{lrr}
\hline & \multicolumn{2}{c}{ Group } \\
\cline { 2 - 3 } Characteristics & Control (n=10) & Obese $(\mathrm{n}=10)$ \\
\hline Age (years) & $42.81 \pm 6.96$ & $41.22 \pm 6.84$ \\
Body weight $(\mathrm{kg})$ & $63.51 \pm 5.25$ & $81.56 \pm 6.22^{\mathrm{a}}$ \\
BMI $\left(\mathrm{kg} / \mathrm{m}^{2}\right)$ & $22.79 \pm 1.43$ & $30.36 \pm 0.94^{\mathrm{a}}$ \\
Fat mass $(\mathrm{kg})$ & $13.33 \pm 3.82$ & $29.85 \pm 5.21^{\mathrm{a}}$ \\
Triglyceride levels (mmol/l) & $1.45 \pm 0.22$ & $1.85 \pm 0.31^{\mathrm{a}}$ \\
Total cholesterol levels (mmol/l) & $4.01 \pm 0.83$ & $5.32 \pm 0.62^{\mathrm{a}}$ \\
HDL-C levels $(\mathrm{mmol} / \mathrm{l})$ & $1.13 \pm 0.41$ & $0.82 \pm 0.21^{\mathrm{a}}$ \\
LDL-C levels $(\mathrm{mmol} / \mathrm{l})$ & $2.53 \pm 0.42$ & $3.36 \pm 0.63^{\mathrm{a}}$ \\
TNF- $\alpha$ levels $(\mathrm{pg} / \mathrm{ml})$ & $2.52 \pm 0.36$ & $3.91 \pm 0.52^{\mathrm{a}}$ \\
IL-6 levels $(\mathrm{pg} / \mathrm{ml})$ & $4.26 \pm 0.95$ & $7.53 \pm 1.26^{\mathrm{a}}$ \\
\hline
\end{tabular}

BMI, body mass index; HDL-C, high-density lipoprotein cholesterol; LDL-C, low-density lipoprotein cholesterol. ${ }^{\mathrm{a}} \mathrm{P}<0.05$ compared with the control group.

$0.5 \mathrm{~kg}$. Fat mass was measured using the bioelectric impedance method with a body FM analyzer (Tanita TBF-300; Tanita Corp., Tokyo, Japan) according to the manufacturer's instructions. This method has been validated for Asian children (23) and adults (24) and has been used by us in previous studies $(25,26)$. The subjects were instructed to stand barefoot on the metal sole plates of the machine. Gender and height details were entered manually into the system. The measurement of impedance uses a standard $50 \mathrm{kHz}-0.8 \mathrm{~mA}$ sine wave constant current. BMI was calculated as weight $(\mathrm{kg})$ divided by the square of height $(\mathrm{m})$. Subjects with a BMI $\geq 28 \mathrm{~kg} / \mathrm{m}^{2}$ were categorized as obese according to the criteria for the Chinese population (27). Blood samples were collected after $12 \mathrm{~h}$ of overnight fasting. The samples were left to coagulate at $4^{\circ} \mathrm{C}$ and then centrifuged at 3,000 rpm for $15 \mathrm{~min}$ to extract serum. None of the patients were acutely ill, or showed any clinical evidence of endocrine diseases. The clinical characteristics of the subjects are presented in Table I. Information on age, height, alcohol consumption, cigarette smoking and physical activity at work and at leisure was obtained from questionnaires. Following anesthesia, samples of subcutaneous adipose tissue (average, 1.0-1.5 g) were obtained from the incision site 10-20 min after surgery commenced and frozen below $-80^{\circ} \mathrm{C}$ prior to the detection of CaSR mRNA and protein expression. Informed consent was obtained from the donors and the study was approved by the Ethics Committee of Harbin Medical University.

Animals and diet. In this study, 48 male Wistar rats (weight, 180-220 g) from the Shanghai Laboratory Animal Center, Chinese Academy of Sciences (SLACCAS; Shanghai, China) were housed individually in stainless steel cages in an animal room at a constant temperature $\left(22 \pm 3^{\circ} \mathrm{C}\right)$ and a 12-h light/dark cycle. For a 10 -week period, 12 rats were fed a standard diet (STD) and 36 rats were fed a high-fat diet (HFD) based on 
Table II. Ingredients of the diets used for feeding the rats.

\begin{tabular}{lcc}
\hline & \multicolumn{2}{c}{ Amount (g/100 g diet) } \\
\cline { 2 - 3 } Ingredients & STD & HFD \\
\hline Casein & 20 & 20 \\
L-cysteine & 0.3 & 0.3 \\
L-methionine & 0.16 & 0.16 \\
Carbohydrates & $66.84^{\mathrm{a}}$ & $55.84^{\mathrm{b}}$ \\
Fat & $7.00^{\mathrm{c}}$ & $18.00^{\mathrm{d}}$ \\
Cellulose & 1 & 1 \\
Vitamin mix, AIN-93G & 1 & 1 \\
Mineral mix, AIN-93G & 3.5 & 3.5 \\
Choline bitartrate & 0.2 & 0.2 \\
(50\% choline) & & \\
Sources of energy (\%) & & 17 \\
Protein & 20 & 48 \\
Carbohydrates & 65 & 35 \\
Fat & 15 & \\
\hline
\end{tabular}

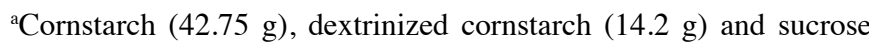
(11 g); ${ }^{b}$ cornstarch (22.75 g), dextrinized cornstarch (14.2 g) and sucrose $(15 \mathrm{~g})$; ' soybean oil; ${ }^{\mathrm{d}}$ lard $(14.0 \mathrm{~g})$ plus soybean oil $(4.0 \mathrm{~g})$. STD, standard diet group; HFD, high-fat diet group. $n=12$ per group.

a purified AIN-93G diet (28). Distilled water was provided ad libitum. The ingredients of the diets are presented in Table II. The rats were weighed weekly during the 10 -week experimental period. Food consumption was measured daily. After the 10-week period, 36 rats were divided into 3 groups according to weight gain, with the lower $33 \%$ of the rats having gained no additional weight, the upper $33 \%$ of the rats having become obese, and the remaining $33 \%$ of the rats having gained moderate weight. The obese and control rats were fasted for $12 \mathrm{~h}$, then anesthetized using pentobarbital $(15-20 \mathrm{mg} / \mathrm{kg}$, intraperitoneal) and sacrificed by exsanguination from the abdominal aorta. The blood samples were centrifuged at 3,000 rpm for $15 \mathrm{~min}$ to extract serum. Peri-renal, omental and epididymal fat pads were dissected from each animal. Tissues were weighed immediately after dissection to avoid evaporative weight loss, and then frozen at $-80^{\circ} \mathrm{C}$ for subsequent analysis. Visceral fat content was calculated as follows: 100 (perirenal + epididymal + omental fat pads)/body weight. The animal care and experimental procedures were approved by the Animal Experimental Committee of Harbin Medical University.

Measurement of serum lipid concentrations. The human and rat serum triglyceride (TG), total cholesterol (TC) and high-density lipoprotein cholesterol (HDL-C) levels were assayed by standard enzymatic colorimetric methods using commercial kits (BioSino Biotechnology, Beijing, China) and with an auto-analyzer (Autolab PM 4000; AMS Corp., Rome, Italy). Low-density lipoprotein cholesterol (LDL-C) levels were calculated using the equation presented in the study by Friedewald et al (29).
Measurement of serum inflammatory cytokine levels. Human and rat serum levels of tumor necrosis factor- $\alpha$ (TNF- $\alpha$ ) and interleukin-6 (IL-6) were measured using commercial ELISA kits (R\&D Systems, Minneapolis, MN, USA) according to the manufacturer's instructions.

Measurement of serum amino acid levels. Human serum amino acid concentrations were determined using high performance liquid chromatography (HPLC) as previously described (30). Briefly, serum samples were spiked with acetonitrile, vortex-mixed, centrifuged and the supernatant was recovered. An Alliance 2695 Separations Module and a 2487 UV detector from Waters Corp., (Milford, MA, USA) were used for the HPLC analysis. Derivatization and gradient of serum amino acids were performed according to the manufacturer's instructions.

Measurement of serum calcium, vitamin D and PTH concentrations. Human serum total calcium levels were measured by the arsenazo III dye method using a commercial calcium kit (Kehua Bio-Engineering Co., Ltd., Shanghai, China). 25-Hydroxy vitamin $\mathrm{D}_{3}\left(25(\mathrm{OH}) \mathrm{D}_{3}\right)$ was measured by ultra performance liquid chromatography (UPLC). Proteins in $100 \mu \mathrm{l}$ serum were precipitated by the addition of $200 \mu \mathrm{l}$ acetonitrile. Samples were vortexed and centrifuged at 10,000 rpm. Supernatants were separated into new $2-\mathrm{ml}$ tubes and diluted by the addition of $100 \mu \mathrm{l}$ distilled water. $25(\mathrm{OH}) \mathrm{D}_{3}$ was extracted using an Oasis HLB 96-well $\mu$ Elution Plate (Waters Corp.) and detected by Acquity UPLC (Waters Corp.). PTH levels were measured using an Intact PTH ELISA kit (Alpco Diagnostics, Salem, NH, USA) according to the manufacturer's instructions.

Measurement of $\left[\mathrm{Ca}^{2+}\right]_{i}$ and cAMP concentrations. Rat adipocytes were isolated from epididymal fat pads from the obese and control rats by washing, mincing, collagenase (Invitrogen Life Technologies, Grand Island, NY, USA) digestion and filtration of the cells, as previously described (9) according to the method presented in the study by Rodbell (31). Adipocytes were loaded with fluo-3 AM and then $\left[\mathrm{Ca}^{2+}\right]_{\mathrm{i}}$ levels were measured by laser scanning confocal microscopy (ECLIPSE TE2000-E; Nikon, Tokyo, Japan) as previously described (9). The florescence intensity value of the obesity group is expressed as a percentatage of the control group. The intracellular cAMP concentration was measured using a cAMP assay kit (Assay Designs, Ann Arbor MI, USA) according to the manufacturer's instructions. The data are expressed as pmol cAMP/mg total protein. Protein concentrations were measured using a BCA kit (Beyotime Institute of Biotechnology, Haimen, China).

Extraction of total RNA and quantitative reverse transcription PCR ( $q R T-P C R)$ analyses. Total RNA was isolated from $0.2 \mathrm{~g}$ human subcutaneous fat, or rat perirenal, epididymal or omental fat pads using TRIzol reagent (Invitrogen Life Technologies) and $1 \mu \mathrm{g}$ of total RNA was used to synthesize cDNA using random primers according to the manufacturer's instructions (Invitrogen Life Technologies). The qRT-PCR amplification procedure was carried out as follows: samples were pre-denatured at $95^{\circ} \mathrm{C}$ for $10 \mathrm{~min}$ and then subjected to 40 cycles of amplification consisting of $15 \mathrm{sec}$ at $95^{\circ} \mathrm{C}$, $30 \mathrm{sec}$ at $60^{\circ} \mathrm{C}$ and $30 \mathrm{sec}$ at $72^{\circ} \mathrm{C}$. $\beta$-actin was used as the 
Table III. Primer sequences, annealing temperature and number of cycles.

\begin{tabular}{|c|c|c|c|c|c|}
\hline Primer & & Sequence & Length (bp) & Annealing temperature $\left({ }^{\circ} \mathrm{C}\right)$ & No. of cycles \\
\hline CaSR & $\begin{array}{l}\text { Sense } \\
\text { Antisense }\end{array}$ & $\begin{array}{l}\text { 5'ATGACTTCTGGTCCAATGAG3' } \\
\text { 5'TGCGGAACTTGATAAACAC3' }\end{array}$ & 156 & 60 & 40 \\
\hline$\beta$-actin & $\begin{array}{l}\text { Sense } \\
\text { Antisense }\end{array}$ & $\begin{array}{l}\text { 5'ACTATCGGCAATGAGCG3' } \\
\text { 5'GAGCCAGGGCAGTAATCT3' }\end{array}$ & 220 & 60 & 40 \\
\hline
\end{tabular}

CaSR, calcium-sensing receptor.

internal control. The expression levels of each mRNA were determined with the ABI Prism 7500 Fast Real-Time PCR system (Applied Biosystems, Foster City, CA, USA) using a SYBR-Green PCR Master mix (Applied Biosystems). Samples were analyzed using the $2^{-\Delta \Delta C t}$ method (32). The sequences of the primers (Sangon Biotech Co., Ltd., Shanghai, China) are presented in Table III.

Western blot analysis. CaSR protein expression in white adipose tissue was determined by western blot anlysis. Human subcutaneous fat, or rat perirenal, epididymal or omental adipose tissue $(0.5 \mathrm{~g})$ was washed twice with ice-cold PBS, crushed in a mortar with liquid nitrogen, and then lysed in cold lysis butter (Beyotime) for $30 \mathrm{~min}$. The lysates were centrifuged at $12,000 \mathrm{rpm}$ for $20 \mathrm{~min}$ at $4^{\circ} \mathrm{C}$. Protein concentrations were measured using a BCA protien assay kit (Beyotime). A CaSR band of $121 \mathrm{kDa}$ was identified under reducing conditions (samples were heat denatured in SDS-PAGE loading buffer supplemented with $5 \% \beta$-mercaptoethanol). Equal amounts of protein were separated by SDS-PAGE and electro-transferred onto polyvinylidene difluoride membranes (Invitrogen Life Technologies). The membranes were blocked with $1 \%$ BSA and probed overnight with primary antibodies against CaSR and $\beta$-actin (Abcam, Cambridge, UK). The membranes were then washed 3 times with TBS-T buffer (150 mmol/1 NaCl, $20 \mathrm{mmol} / 1$ Tris-HCl, $\mathrm{pH} \mathrm{7.4,0.05 \%}$ Tween-20) for $10 \mathrm{~min}$, incubated with rabbit IgG antibody (Santa Cruz Biotechnology, Santa Cruz, CA, USA) for $1 \mathrm{~h}$ at $37^{\circ} \mathrm{C}$, and then washed again 3 times with TBS-T buffer. The blots were detected using alkaline phosphatase (Promega Corporation, Madison, WI, USA). The protein bands were subjected to autoradiography (Champ-Gel-3200, Sage Creation, China), and densitometry was quantified by Alpha EaseFc software (FluorChem, Alpha Innotech, San Leandro, CA, USA). Data are presented as the ratios of target protein to $\beta$-actin. Experiments were replicated at least 3 times and representative blots are shown.

Statistical analysis. Differences were analyzed for significance using the Student's t-test. Data were expressed as the means \pm SD and a P-value $<0.05$ was considered to indicate a statistically significant difference. ANOVA was used to compare serum amino acid levels between the obese and normal weight controls, adjusting for age, smoking history, alcohol consumption and physical activity at work and at leisure. Each value is the mean of at least 3 repetitive experiments in each
Table IV. Body weight, fat content and serum lipid concentrations in the obese and control rats.

\begin{tabular}{lrr}
\hline Characteristics & Control $(\mathrm{n}=12)$ & Obese $(\mathrm{n}=12)$ \\
\hline Body weight $(\mathrm{g})$ & $471.22 \pm 28.9$ & $520.8 \pm 39.4^{\mathrm{a}}$ \\
Fat content $(\%)$ & $3.92 \pm 1.24$ & $5.42 \pm 1.05^{\mathrm{a}}$ \\
Triglyceride levels $(\mathrm{mmol} / \mathrm{l})$ & $0.73 \pm 0.24$ & $1.26 \pm 0.34^{\mathrm{a}}$ \\
Total cholesterol levels $(\mathrm{mmol} / \mathrm{l})$ & $1.72 \pm 0.31$ & $2.12 \pm 0.23^{\mathrm{a}}$ \\
HDL-C levels $(\mathrm{mmol} / \mathrm{l})$ & $0.84 \pm 0.23$ & $0.64 \pm 0.12^{\mathrm{a}}$ \\
LDL-C levels $(\mathrm{mmol} / \mathrm{l})$ & $0.54 \pm 0.22$ & $0.90 \pm 0.16^{\mathrm{a}}$ \\
TNF- $\alpha$ levels $(\mathrm{pg} / \mathrm{ml})$ & $42.38 \pm 4.61$ & $56.22 \pm 6.21^{\mathrm{a}}$ \\
IL-6 levels $(\mathrm{pg} / \mathrm{ml})$ & $10.53 \pm 2.68$ & $18.62 \pm 2.65^{\mathrm{a}}$ \\
\hline
\end{tabular}

HDL-C, high-density lipoprotein cholesterol; LDL-C, low-density lipoprotein cholesterol. ${ }^{a} \mathrm{P}<0.05$ compared with the control group.

group. Statistical analyses were performed using the SPSS 13.0 statistical program (version 13.01S; Beijing Stats Data Mining Co., Ltd., Beijing, China).

\section{Results}

Lipids and inflammatory factors in obese human and rat serum. The concentrations of TG, TC and LDL-C, but not HDL-C, were significantly higher in the obese versus the non-obese individuals. The serum levels of TNF- $\alpha$ and IL-6 were also significantly higher in the obese versus non-obese individuals (Tables I and IV), suggesting a hyperlipidemic and inflammatory status in obese individuals. There were no significant differences between the groups as regards age, smoking history, alcohol consumption and physical activity (data not shown).

Calcium, vitamin D and PTH concentrations in human serum. Calcium is the primary agonist of CaSR. In this study, serum calcium concentrations in the obese group did not differ from those in the control group (Fig. 1A). Vitamin D has been reported to regulate the expression of $\mathrm{CaSR}$ in several types of tissue. $25(\mathrm{OH}) \mathrm{D}_{3}$ is the main metabolite of vitamin $\mathrm{D}$ in serum, and is regarded as the best indicator of the overall vitamin D status (33). Our results revealed that serum $25(\mathrm{OH}) \mathrm{D}_{3}$ levels were significantly lower in the obese versus non-obese individuals (Fig. 1B). The main role of CaSR is to maintain 
A

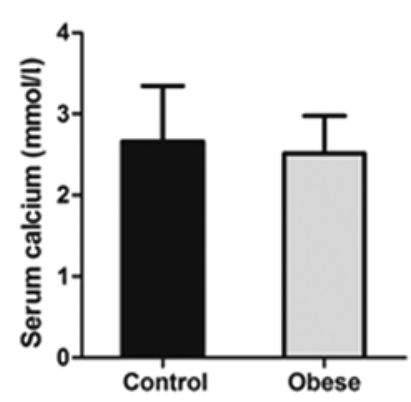

B

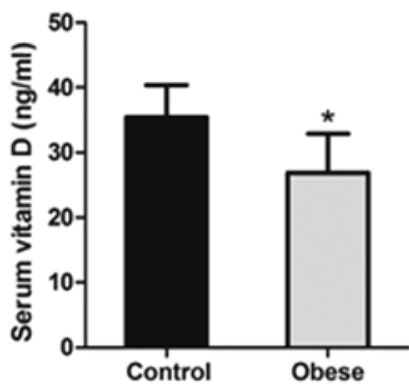

$\mathbf{C}$

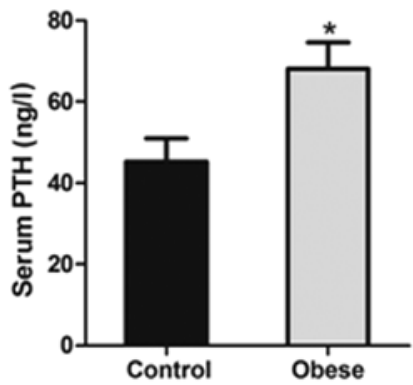

Figure 1. Serum concentrations of total calcium, vitamin D and parathyroid hormone (PTH). (A) Serum total calcium, (B) vitamin D and (C) PTH levels in 10 obese males and 10 non-obese controls were measured using the arsenazo III dye method, UPLC and ELISA, respectively. Values are the means $\pm \mathrm{SD}$. ${ }^{*} \mathrm{P}<0.05$ versus the control group.

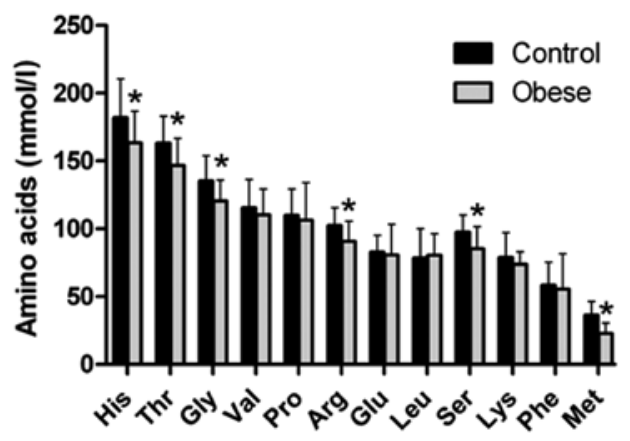

Figure 2. Serum concentrations of amino acids. Serum levels of amino acids from 10 obese and 10 non-obese controls were determined by HPLC. Values are the means $\pm \mathrm{SD} .{ }^{*} \mathrm{P}<0.05$ versus the control group, adjusted for age, smoking history, alcohol consumption and physical activity at work and at leisure. His, histidine; Thr, threonine; Gly, glycine; Val, valine; Pro, proline; Arg, arginine; Glu, glutamate; Leu, leucine; Ser, serine; Lys, lysine; Phe, phenylalanine; Met, methionine.

calcium concentrations by regulating the secretion of PTH. In this study, PTH levels were found to be higher in the obese subjects compared with the control group (Fig. 1C).
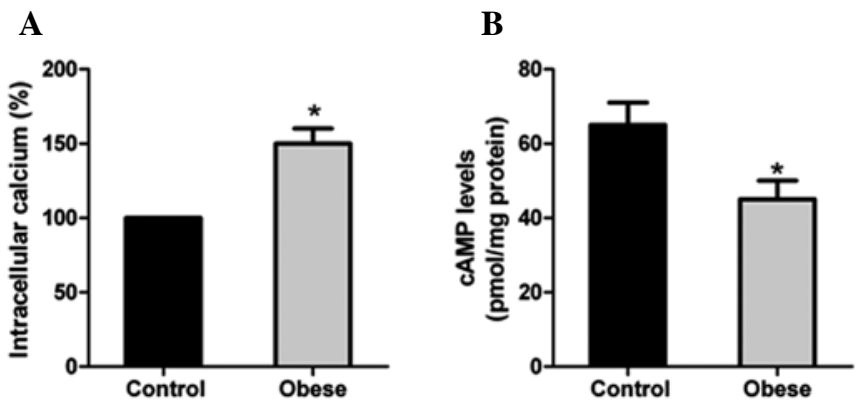

Figure 3. Levels of (A) intracellular calcium and (B) cyclic adenosine monophosphate (cAMP) in rat adipocytes. Intracellular calcium and cAMP were measured by laser scanning confocal microscopy and ELISA, respectively. Values for intracellular calcium in the obese group are expressed as a percentatage of the control group. Values for cAMP are the means $\pm \mathrm{SD}$. ${ }^{*} \mathrm{P}<0.05$ versus the control group.

Amino acid levels in human serum. Amino acids can regulate a number of cellular responses, such as controlling rates of transcription and translation through the activation or inhibition of specific signaling pathways. It has been shown that CaSR is a molecular target for L-amino acids (15). Accordingly, in this study, 10 amino acids in human serum were measured using HPLC. Among these, serum histidine, threonine, glycine, arginine, serine and methionine were found to be significantly lower in the obese versus non-obese individuals, after adjusting for age, smoking history, alcohol consumption and physical activity at work and at leisure (Fig. 2). Other amino acids measured showed no differences between these 2 groups.

$\left[\mathrm{Ca}^{2+}\right]_{i}$ and cAMP levels in rat adipocytes. It has been reported that $\left[\mathrm{Ca}^{2+}\right]_{\mathrm{i}}$ and cAMP are 2 critical secondary messengers modulated by the activation of CaSR (3). In this study, we observed that $\left[\mathrm{Ca}^{2+}\right]_{\mathrm{i}}$ concentrations increased, while cAMP levels decreased in obese rat adipocytes compared with the control rat adipocytes (Fig. 3).

CaSR gene and protein levels in human and rat white adipose tissue. As calcium, vitamin $\mathrm{D}$, amino acids and the inflammatory cytokines, TNF- $\alpha$ and IL-6, have been reported to affect the expression of CaSR in vitro $(3,21)$, we further investigated the expression of CaSR in the obese state. The results revealed that the gene and protein expression of CaSR in both the human and rat white adipose tissue did not differ between the obese and non-obese groups (Fig. 4). These results suggest that CaSR expression in fat tissue is not altered in obese individuals.

\section{Discussion}

CaSR plays a vareity of roles in different types of tissue in the body. In adipose tissue, ours, as well as other studies have demonstrted that after being activated, CaSR plays an antilipolytic role in adipose cells $(6,7)$. CaSR has been shown to affect adipocyte differentiation through the regulation of transcriptional factors (8). In vivo, we have reported that the expression of CaSR in white adipose tissue is upregulated by a low calcium diet (9), but we did not elucidate its mechanisms of action in obesity. 
A
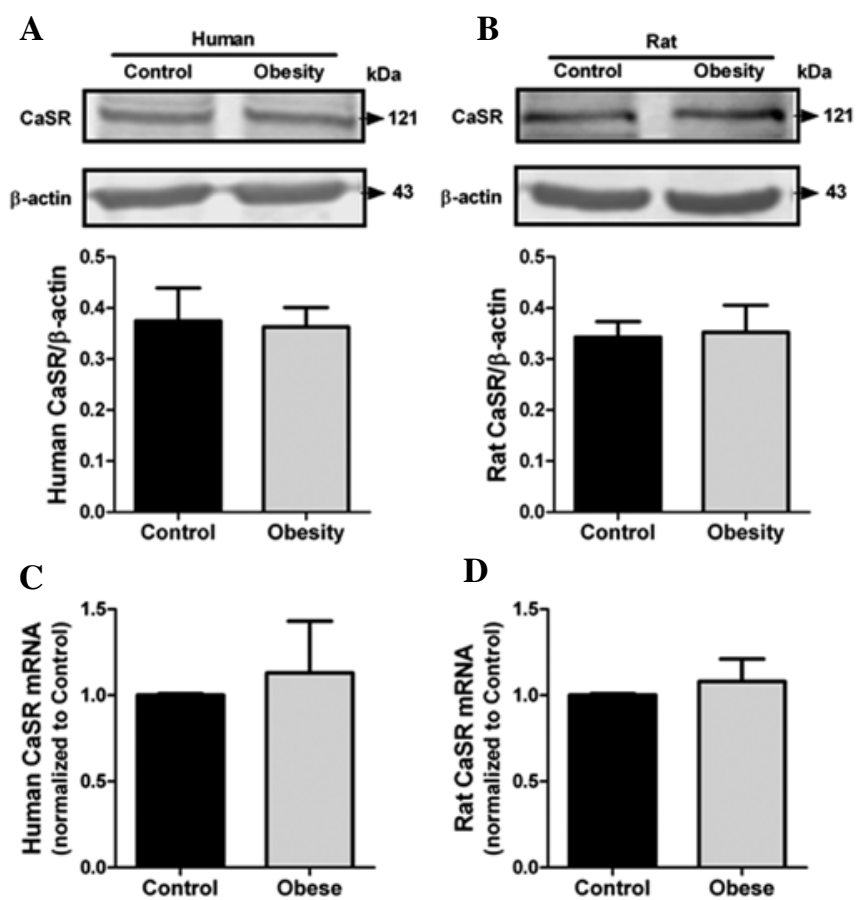

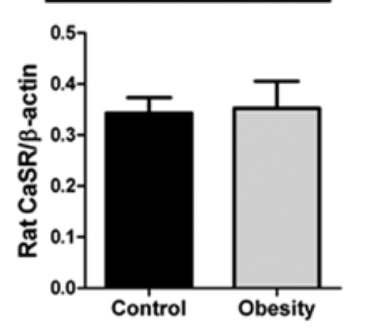

D

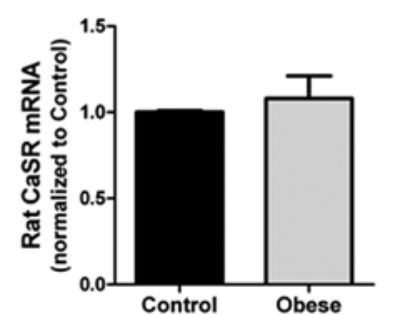

Figure 4. Protein and gene expression of the calcium-sensing receptor (CaSR) in human adipose tissue. The expression of (A and B) CaSR protein and (C and D) gene expression in human and rat adipose tissue were determined by western blot analysis and qRT-PCR, respectively. The experiments were performed in triplicate. Values are the means \pm SD.

CaSR, discovered in 1993, is best known for its role in regulating the synthesis and secretion of $\mathrm{PTH}$ in the parathyroid glands. Since then, it has been detected in many cell types and has been shown to have various cell-dependent functions (3). One of these functions is its involvement in inflammatory events which are characterized by high levels of inflammatory cytokines $(34,35)$. The expression of CaSR has been reported to be upregulated in the presence of IL-6 and TNF- $\alpha$ in different cell types (36-38). This has led to a speculation that the obesity-induced inflammatory status may play a crucial role in the upregulation of CaSR expression. Recently, Cifuentes et al demonstrated that the obesity-associated inflammatory cytokines, TNF- $\alpha$ and IL-6, increase CaSR expression in adipocytes (21). However, there has been a lack of in vivo evidence to support this conclusion. Therefore, in this study, we determined the status of CaSR in adipose tissue from obese humans and rats. Our results revealed that there were higher levels of TNF- $\alpha$ and IL-6 in obese individuals; these data are in agreement with those from previous studies showing elevated serum cytokine levels in humans and animals with excess adiposity (39). However, CaSR expression was not significantly altered in the obese versus non-obese individuals in the present study. These data are inconsistent with those presented in the study by Cifuentes et al, who demonstrated that CaSR expression was increased by obesity-associated pro-inflammatory cytokines (21). The mRNA and/or protein expression of CaSR can change under various circumstances. For example, calf parathyroid cells show rapid and marked reductions in CaSR mRNA and protein levels after being cultured (40). Furthermore, the renal expression of CaSR has

been shown to increase following treatment with 1,25-dihydroxyvitamin D (17). Phosphorus intake has also been reported to be associated with a reduced $\mathrm{CaSR}$ mRNA and protein expression in the parathyroid glands (18). As described above, although obesity is associated with a state of inflammation, the level is chronic and low. Moreover, it is difficult to evaluate the local physiological concentrations of cytokines within obese adipose tissue, which depends on the secretion and clearance capacity of the individual. The cytokine concentrations in presented in the study by Cifuentes et al were much higher than other reported circulating levels (21). In addition, there are many other active components that may also play roles in modulating CaSR expression. As such, we believe our results to be more consistent with the actual physiological state of obesity.

Although we did not observe any significant changes in CaSR expression in adipose tissue in obese individuals, the role of CaSR in adipocytes may also be attributed to its allosteric regulation under conditions of obesity. According to its structure and known function, the most direct evidence to judge the allosteric regulation of CaSR is whether it can lead to a reduction in cAMP levels and an increase in $\left[\mathrm{Ca}^{2+}\right]_{\mathrm{i}}$ release in a short period when its expression remains constant. Our results revealed that cAMP levels were significantly reduced, while $\left[\mathrm{Ca}^{2+}\right]_{\mathrm{i}}$ levels were increased in obese rat adipocytes compared with the control group. These data are consistent with the data from our previous studies, demonstrating a rapid increase in $\left[\mathrm{Ca}^{2+}\right]_{\mathrm{i}}$ levels and a decreased cAMP accumulation in response to a CaSR agonist in adipocytes $(7,8)$.

There are a variety of stimuli that can be sensed by CaSR in the obese state. Extracellular calcium has been the primary agonist since the discovery of CaSR. Vitamin D is a factor that has been identified to regulate CaSR expression in the kidneys (41). L-amino acids have also been shown to be CaSR ligands (15). Any changes in the above stimuli may activate or inactivate CaSR allosterically, or modulate its expression, and finally achieve their biological functions. In this study, serum calcium levels were the same between the obese and control groups due to the strong ability of the body to maintain calcium homeostasis. Nevertheless, vitamin D and amino acid concentrations were significantly lower in the obese individuals, as has previously been reported by us, as well as others $(30,42)$. Under such circumstances, the expression of CaSR in adipose tissue remains unaltered, further supporting the possibility of allosteric regulation. In this study, although $25(\mathrm{OH}) \mathrm{D}_{3}$ levels were lower in the obese compared with the normal weight subjects, there are some lines of evidence demonstrating that $1,25-\mathrm{di}(\mathrm{OH})_{2} \mathrm{D}_{3}$, the biologically active form of vitamin $\mathrm{D}_{3}$, is elevated in obese humans (43-45). We have previously reported that the elevation of $1,25-\mathrm{di}(\mathrm{OH})_{2} \mathrm{D}_{3}$ stimulates the expression of CaSR in adipocytes under low calcium conditions and that this is associated with an increase in $\left[\mathrm{Ca}^{2+}\right]_{\mathrm{i}}$ levels (9). However, in this study, no difference in CaSR expression in adipose tissue was observed between the obesity group and the normal weight group.

Free L-amino acids are essential molecules in biological systems. Cellular sensing of L-amino acids modulates diverse cellular responses. Fluctuating blood levels of amino acids have an important impact on body protein, carbohydrate and calcium metabolism and perhaps tissue growth and development. Thus, the low levels of amino acids observed in obese individuals 
may be a regulator of body weight. Low amino acid levels have been shown to be associated with high levels of PTH, which potentially involve amino acid sensing by CaSR (46). PTH has been shown to stimulate an increase in $\left[\mathrm{Ca}^{2+}\right]_{\mathrm{i}}$ levels in adipocytes (47), which may finally lead to fat accumulation mainly by the activation of adipocyte phosphodiesterase (PDE) and a reduction in cAMP levels, leading to a decrease in hormonesensitive lipase (HSL) phosphorylation, by stimulating the expression and activity of fatty acid synthase (FAS) (48-50). In this study, serum PTH levels were significantly higher in the obese subjects compared with the control group. Therefore, we hypothesized that the increased $\left[\mathrm{Ca}^{2+}\right]_{\mathrm{i}}$ and the decreased cAMP levels can be mediated by CaSR through sensing the changes in serum amino acids under conditions of obesity. Of course, there are numerous other unknown CaSR regulators in the serum that need to be further identified.

In conclusion, the results from the present study demonstrate that the expression of CaSR in adipose tissue is unaltered in obese individuals with inflammation and low vitamin D and acid amino acid concentrations, providing preliminary evidence that CaSR may play a role through sensing the changes in amino acids in obese individuals rather than through its expression.

\section{Acknowledgements}

We thank Dr Gang Li from the Second Affiliated Hospital of Harbin Medical University for recruiting human subjects and obtaining fat tissue. This study was funded by grants from the National Natural Science Fund of China key project (no. 81130049) and the Program for New Century Excellent Talents in University of China (no. NCET-10-0148). The sponsors played no role in this study or the decision to submit the manuscript for publication.

\section{References}

1. Obesity: preventing and managing the global epidemic. Report of a WHO consultation. World Health Organ Tech Rep Ser 894: i-xii, 1-253, 2000.

2. Kopelman PG: Obesity as a medical problem. Nature 404: 635-643, 2000.

3. Brown EM and MacLeod RJ: Extracellular calcium sensing and extracellular calcium signaling. Physiol Rev 81: 239-297, 2001.

4. Brown EM, Gamba G, Riccardi D, et al: Cloning and characterization of an extracellular $\mathrm{Ca}(2+)$-sensing receptor from bovine parathyroid. Nature 366: 575-580, 1993.

5. Cifuentes M, Albala C and Rojas C: Calcium-sensing receptor expression in human adipocytes. Endocrinology 146: 2176-2179, 2005.

6. Cifuentes M and Rojas CV: Antilipolytic effect of calciumsensing receptor in human adipocytes. Mol Cell Biochem 319: 17-21, 2008.

7. He Y, Zhang H, Teng J, Huang L, Li Y and Sun C: Involvement of calcium-sensing receptor in inhibition of lipolysis through intracellular CAMP and calcium pathways in human adipocytes. Biochem Biophys Res Commun 404: 393-399, 2011.

8. He YH, He Y, Liao XL, et al: The calcium-sensing receptor promotes adipocyte differentiation and adipogenesis through PPARgamma pathway. Mol Cell Biochem 361: 321-328, 2012.

9. He YH, Song Y, Liao XL, et al: The calcium-sensing receptor affects fat accumulation via effects on antilipolytic pathways in adipose tissue of rats fed low-calcium diets. J Nutr 141: 1938-1946, 2011.

10. Hofer AM and Brown EM: Extracellular calcium sensing and signalling. Nat Rev Mol Cell Biol 4: 530-538, 2003.
11. Chen RA and Goodman WG: Role of the calcium-sensing receptor in parathyroid gland physiology. Am J Physiol Renal Physiol 286: F1005-F1011, 2004.

12. Draznin B, Sussman KE, Eckel RH, Kao M, Yost T and Sherman NA: Possible role of cytosolic free calcium concentrations in mediating insulin resistance of obesity and hyperinsulinemia. J Clin Invest 82: 1848-1852, 1988.

13. Draznin B, Sussman K, Kao M, Lewis D and Sherman N: The existence of an optimal range of cytosolic free calcium for insulin-stimulated glucose transport in rat adipocytes. J Biol Chem 262: 14385-14388, 1987.

14. Byyny RL, LoVerde M, Lloyd S, Mitchell W and Draznin B: Cytosolic calcium and insulin resistance in elderly patients with essential hypertension. Am J Hypertens 5: 459-464, 1992.

15. Conigrave AD, Mun HC and Lok HC: Aromatic L-amino acids activate the calcium-sensing receptor. J Nutr 137 (6 Suppl 1): S1524-S1527, 2007.

16. Emanuel RL, Adler GK, Kifor O, et al: Calcium-sensing receptor expression and regulation by extracellular calcium in the AtT-20 pituitary cell line. Mol Endocrinol 10: 555-565, 1996.

17. Brown AJ, Zhong M, Finch J, et al: Rat calcium-sensing receptor is regulated by vitamin D but not by calcium. Am J Physiol 270: F454-F460, 1996.

18. Brown AJ, Ritter CS, Finch JL and Slatopolsky EA: Decreased calcium-sensing receptor expression in hyperplastic parathyroid glands of uremic rats: role of dietary phosphate. Kidney Int 55: 1284-1292, 1999

19. Antuna-Puente B, Feve B, Fellahi S and Bastard JP: Adipokines: the missing link between insulin resistance and obesity. Diabetes Metab 34: 2-11, 2008.

20. Calabro P, Golia E, Maddaloni V, et al: Adipose tissue-mediated inflammation: the missing link between obesity and cardiovascular disease? Intern Emerg Med 4: 25-34, 2009.

21. Cifuentes M, Fuentes C, Mattar P, et al: Obesity-associated proinflammatory cytokines increase calcium sensing receptor (CaSR) protein expression in primary human adipocytes and LS14 human adipose cell line. Arch Biochem Biophys 500: 151-156, 2010.

22. Cifuentes M, Fuentes C, Tobar N, et al: Calcium sensing receptor activation elevates proinflammatory factor expression in human adipose cells and adipose tissue. Mol Cell Endocrinol 361: 24-30, 2012.

23. Sung RY, Lau P, Yu CW, Lam PK and Nelson EA: Measurement of body fat using leg to leg bioimpedance. Arch Dis Child 85: 263-267, 2001.

24. Nunez C, Gallagher D, Visser M, Pi-Sunyer FX, Wang Z and Heymsfield SB: Bioimpedance analysis: evaluation of leg-to-leg system based on pressure contact footpad electrodes. Med Sci Sports Exerc 29: 524-531, 1997.

25. Li Y, Wang C, Zhu K, Feng RN and Sun CH: Effects of multivitamin and mineral supplementation on adiposity, energy expenditure and lipid profiles in obese Chinese women. Int J Obes (Lond) 34: 1070-1077, 2010.

26. Huang L, Xue J, He Y, et al: Dietary calcium but not elemental calcium from supplements is associated with body composition and obesity in Chinese women. PLoS One 6: e27703, 2011.

27. Li LM, Rao KQ, Kong LZ, et al: A description on the Chinese national nutrition and health survey in 2002. Zhonghua Liu Xing Bing Xue Za Zhi 26: 478-484, 2005 (In Chinese).

28. Reeves PG, Nielsen FH and Fahey GC Jr: AIN-93 purified diets for laboratory rodents: final report of the American Institute of Nutrition ad hoc writing committee on the reformulation of the AIN-76A rodent diet. J Nutr 123: 1939-1951, 1993.

29. Friedewald WT, Levy RI and Fredrickson DS: Estimation of the concentration of low-density lipoprotein cholesterol in plasma, without use of the preparative ultracentrifuge. Clin Chem 18: 499-502, 1972.

30. Niu YC, Feng RN, Hou Y, et al: Histidine and arginine are associated with inflammation and oxidative stress in obese women. Br J Nutr 108: 57-61, 2012.

31. Rodbell M: Metabolism of isolated fat cells. I. Effects of hormones on glucose metabolism and lipolysis. J Biol Chem 239: $375-380,1964$.

32. Livak KJ and Schmittgen TD: Analysis of relative gene expression data using real-time quantitative PCR and the 2(-Delta Delta C(T)) Method. Methods 25: 402-408, 2001.

33. Kimball S, Fuleihan Gel H and Vieth R: Vitamin D: a growing perspective. Crit Rev Clin Lab Sci 45: 339-414, 2008. 
34. Abdullah HI, Pedraza PL, Hao S, Rodland KD, McGiff JC and Ferreri NR: NFAT regulates calcium-sensing receptor-mediated TNF production. Am J Physiol Renal Physiol 290: F1110-F1117, 2006.

35. Wang D, Pedraza PL, Abdullah HI, McGiff JC and Ferreri NR: Calcium-sensing receptor-mediated TNF production in medullary thick ascending limb cells. Am J Physiol Renal Physiol 283: F963-F970, 2002.

36. Canaff L and Hendy GN: Calcium-sensing receptor gene transcription is up-regulated by the proinflammatory cytokine interleukin-1beta. Role of the NF-kappaB pathway and kappaB elements. J Biol Chem 280: 14177-14188, 2005.

37. Nielsen PK, Rasmussen AK, Butters R, et al: Inhibition of PTH secretion by interleukin-1 beta in bovine parathyroid glands in vitro is associated with an up-regulation of the calcium-sensing receptor mRNA. Biochem Biophys Res Commun 238: 880-885, 1997.

38. Toribio RE, Kohn CW, Capen CC and Rosol TJ: Parathyroid hormone (PTH) secretion, PTH mRNA and calcium-sensing receptor mRNA expression in equine parathyroid cells, and effects of interleukin (IL)-1, IL-6, and tumor necrosis factoralpha on equine parathyroid cell function. J Mol Endocrinol 31: 609-620, 2003.

39. Park HS, Park JY and Yu R: Relationship of obesity and visceral adiposity with serum concentrations of CRP, TNF-alpha and IL-6. Diabetes Res Clin Pract 69: 29-35, 2005.

40. Brown AJ, Zhong M, Ritter C, Brown EM and Slatopolsky E: Loss of calcium responsiveness in cultured bovine parathyroid cells is associated with decreased calcium receptor expression. Biochem Biophys Res Commun 212: 861-867, 1995.

41. Yao JJ, Bai S, Karnauskas AJ, Bushinsky DA and Favus MJ: Regulation of renal calcium receptor gene expression by 1,25 -dihydroxyvitamin $D_{3}$ in genetic hypercalciuric stone-forming rats. J Am Soc Nephrol 16: 1300-1308, 2005.
42. Parikh SJ, Edelman M, Uwaifo GI, et al: The relationship between obesity and serum 1,25-dihydroxy vitamin D concentrations in healthy adults. J Clin Endocrinol Metab 89: 1196-1199, 2004.

43. Andersen T, McNair P, Hyldstrup L, et al: Secondary hyperparathyroidism of morbid obesity regresses during weight reduction. Metabolism 37: 425-428, 1988.

44. Bell NH, Epstein S, Greene A, Shary J, Oexmann MJ and Shaw S: Evidence for alteration of the vitamin D-endocrine system in obese subjects. J Clin Invest 76: 370-373, 1985.

45. Bell NH, Epstein S, Shary J, Greene V, Oexmann MJ and Shaw S: Evidence of a probable role for 25-hydroxyvitamin D in the regulation of human calcium metabolism. J Bone Miner Res 3: 489-495, 1988.

46. Conigrave AD, Franks AH, Brown EM and Quinn SJ: L-amino acid sensing by the calcium-sensing receptor: a general mechanism for coupling protein and calcium metabolism? Eur J Clin Nutr 56: 1072-1080, 2002.

47. Ni Z, Smogorzewski M and Massry SG: Effects of parathyroid hormone on cytosolic calcium of rat adipocytes. Endocrinology 135: 1837-1844, 1994.

48. Shi H, Norman AW, Okamura WH, Sen A and Zemel MB: 1alpha,25-Dihydroxyvitamin $\mathrm{D}_{3}$ modulates human adipocyte metabolism via nongenomic action. FASEB J 15: 2751-2753, 2001.

49. Xue B, Greenberg AG, Kraemer FB and Zemel MB: Mechanism of intracellular calcium $\left(\left[\mathrm{Ca}^{2+}\right] \mathrm{i}\right)$ inhibition of lipolysis in human adipocytes. FASEB J 15: 2527-2529, 2001.

50. Zemel MB, Shi H, Greer B, Dirienzo D and Zemel PC: Regulation of adiposity by dietary calcium. FASEB J 14: 1132-1138, 2000. 